\title{
Medicine for a New Age
}

FRANK STANTON, Ph.D.

$I^{1}$ N CINCINNATI 140 years ago, at the opening of what was then our westernmost medical school, Dr. Daniel Drake, president of the New Medical College of Ohio, in his "Inaugural Discourse on Medical Education," said, "Clinical medicine is an unceasing employment of means for the accomplishment of specific or definite objects. Considered in relation to our knowledge of these means, the profession is a science - in relation to the application of them, it is an art. He who acquires the former only is learned; he who relies on the latter alone is ignorant, empirical, and criminal; he who encompasses both reaches the highest attainable perfection."

Perhaps this is where a quondam psychologist can speak up without feeling too defensive. There are many ways of dividing and subdividing the rapidly expanding world of science. We have the earth sciences versus the life sciences. We have the physical sciences versus the behavioral sciences. But Elton Mayo, of Harvard, has divided the sciences into the "successful" and the "unsuccessful." Into the former category he put chemistry and physics; into the latter he put psychology and economics.

That was some time ago, and this state of affairs is not going to last forever. The behavioral sciences, so far, justify inclusion in the "unsuccessful" sciences, in the sense that they have more unknowns in them than they have equations with which to solve them. But for the very reasons which Dr. Drake called forth,

This paper is based on a talk given at the dedication of the Stanford Medical Center, Palo Alto, Calif. Dr. Stanton is president of Columbia Broadcasting System, Inc., and former chairman, Center for Advanced Study in the Behavioral Sciences. the medical sciences, so-called, also belong among the "unsuccessful" sciences because, despite medicine's enormous content of science, it is also an art.

It is interesting to a layman to take a backward glance at the history of medical education in this country. In modern times, I suppose, the opening of the Johns Hopkins Medical School and Hospital in 1893 was a major landmark, with the emergence of those four great men of medicine-Welch, Osler, Halsted, and Kelly. So high had the standards of admission been set that one of Welch's principal worries was whether anyone would arrive to be taught, and Osler said to Halsted, so the story goes, "It is very fortunate we are here as professors, for I greatly doubt if we could qualify as students."

And there is that other landmark: the Flexner Report. It is not very long ago in the scale of history that the Flexner Report on medical education turned things upside down, and this nation assumed concern for the kind and quality of medical education which was to place American physicians and surgeons at the very top of the world's best in their technical skill and qualifications.

It is not for me to say why another problem sometime thereafter began to beset medical education and medical practice, nor could I even say with accuracy when the Age of the Specialist dawned in this country. But certainly there was a time which has not yet drawn to a close when the general practitioner who had once been the mainstay of American medicine declined almost to the role of the preliminary classifier, whose principal function became that of referring the patient to the man who knew all the neck or the knee joint and almost prided 
himself on the narrowness of his specialization. Then it was that we heard the complaint, not yet died out, that the disease and not the patient was being treated, and that the technical side of medicine, the scientific side, was flourishing so mightily, as indeed it was, that the side of medicine which was and will always remain an art was being neglected. "Science is to be studied, but art is to be practiced," said a great Englishman some years ago. He was thinking of literature, not medicine, when he made this remark, but not for nothing does the phrase "the practice of medicine" stay firmly embedded in our language.

In Palo Alto, the Stanford Medical Center offers a unique opportunity. The peninsula community is growing at an explosive rate, but the nearest metropolitan city remains a good 30 miles away. Here are people of every walk of life, in every degree of existence from robust good health to the seriously or chronically ill, of every age and status. And in the midst of this a distinguished medical school and teaching hospital is now provided. The opportunity for students, for physicians, senior and junior, to be in intimate touch with a large cross section of humanity is unparalleled.

This medical center and teaching hospital makes possible a close-working inter-relationship between the total university, the medical school, and the local community. The modern problems of health and medical care require this kind of cooperation. The pattern of illness today has changed from the acute and specifically caused disease to the more chronic, ill-defined trouble based upon a host of interrelated causes not always purely in the domain of medicine. Increasingly, we must bring new batteries to bear on the target. Increasingly, this involves the behavioral sciences, political groups, voluntary agencies, and the whole society.

In general there is a great increase in our knowledge of man as a social human being. Explosive population growth and population shifts have focused attention upon the different incidence of diseases among various groups. Rapid industrialization has brought with it new problems: whether of air pollution or of the control of radiation whose potential impact upon the health of the population requires con- tinuous study and eventual control. Our society does not have clear-cut patterns to follow in the development of medical care programs for the future. The mere multiplication of facilities, excellent though they may be, is not the total answer. Recent studies have shown that only one-sixth of the adults of the lowest socioeconomic group have availed themselves of polio vaccine in New York City, despite the fact that every conceivable method has been used to make this vaccine conveniently and freely available. Research in human motivation is essential if we are to close the gap between what we know how to do and what we are actually able to accomplish.

The Palo Alto area is a thriving community peopled largely by self-sufficient citizens who are willing to pay for, and who will demand, the best of medical service. But even such citizens as these need more than a little medical education. Any large hospital can cite case histories involving wealthy citizens who have delayed seeking treatment for a serious symptom to beyond the point where cure can be offered. At the other end of the scale, this general area also has its share of lower socioeconomic groups. Migratory workers, for example, bring with them their own set of social and medical problems. Their habits of living, their particular social values, have a potentially greater impact upon the way in which they react to disease and treatment. It is not enough to maintain excellent clinic facilities and an expert staff of medical scientists. We must make sure that all the groups in this area will avail themselves of these resources when they should and to the extent they should. Here again the behavioral scientist is involved. The doctor himself cannot always see to it that what he recommends is really being carried out.

It has been pointed out that many factors beyond medicine enter into our lowering death rate. The mass media of communications have taught some people more healthful habits. The rising standard of living means better food and better sanitation. And I believe I reflect sound medical opinion when I quote that "with the exception of damage through excessive radiation, control measures for the diseases still to be conquered will rely less on the mass preventive measures of the past and more on preven- 
tive measures undertaken by the individual on his own behalf." Such mass measures as can be taken in the fight against disease have been taken, and have succeeded. The conquest of cancer, heart disease, and mental illness, for example, is going to depend on widespread private cooperation.

A noted social scientist once said that if problems still exist it means that present tools and concepts must be considered inadequate. This in turn demands that we seek new resources, new formulations of ideas. The fact that we do not now know how to control 17 of the 19 leading causes of death is a certain indication of the inadequacy of our present resources. There are a number of clues which offer promise in an approach to these problems.

The first clue is our tendency today to make our approach problem centered rather than agency centered. It is not what the doctor or the health department wants to do which is the answer; it is what the problem demands. We must become problem centered with less reliance on fixed standards, patterns, and solutions. A second clue is the increasing reliance we are now putting upon the comprehensive method, and in attempting, whenever possible, to extend this into the social sciences. The supreme importance of the citizen as a central figure in all health programs is a further clue. We must see that he is prepared. We must communicate with him. We must learn to give increasing scientific weight to the social factors which move him.

Let me now expand for a moment on my theme as someone in or on the fringes of the behavioral sciences. There may be some doubt among you as to the meaning of the term. I can sympathize with that, since in a large measure the behavioral sciences are sciences struggling to be born, and it is not an easy birth. Some of these sciences (biology, for example) are fully and firmly established; some others (let us say political science, so-called) are more science by hope and courtesy than by establishment. But in their whole gamut they are concerned with the interactions of man and man, and as such they are not subject to the rigorous laws discovered or awaiting discovery that govern the atom and the molecule. Whatever they are-be they anthropology, psychology, history, or sociology - they demand acute and incessant observation, and they call for enormous powers of generalization. In this they resemble medicine, but they have not yet found their Newton or their Einstein, or for that matter their Pasteur or their Lister. But I, for one, would certainly classify medicine among the behavioral sciences, since, as we have seen, it is not all science and since its locus is that baffling and unpredictable entity, the human being.

In 1959 a small book was published whose title is the challenging question "Can Man be Modified?" Its author, the biologist Jean Rostand, son of the author of "Cyrano de Bergerac," gave it the subtitle, "Predictions of Our Biological Future." And the major prediction, from the biologist's point of view, was yes, most certainly man can be modified. Although the author stressed how little of absolute knowledge the biological sciences have been able to come by, his list of possible miracles was highly impressive, including, of course, children conceived without the active aid of a father and, also, born of a mother who might not be genetically theirs. Professor Rostand gets no farther than page 14 before he alludes to experiments of Briggs and King with these words: "This new technique of generation from the nucleus of a body cell would in theory enable us to create as many identical individuals as might be desired. A living creature would be printed in hundreds of thousands of copies, all of them real twins. This would, in short, be human propagation by cuttings, capable of assuring the indefinite reproduction of the same individual-of a great man, for example!"

Judging from the examples of a few of the authentically great men I think I have known, I am not dead sure that their "indefinite reproduction" would necessarily be a boon to the race. And a nation or a state consisting of all chiefs and no Indians might give us some tougher behavioral problems to handle than we have to deal with in our present well-accustomed chaos. However, I do not mean to be glib about any of the possible miracles of the future. I hope we all live to see a great many of them come true. Although Professor Rostand's book is written for a popular audience, the recent solid achievement in genetics, as represented by Stanford's own Nobel Laureate, Joshua Lederberg, fur- 
nishes a verification for its really momentous line: "The upshot of all this," says the author, "is that from now on we possess the means of acting upon life."

Let me go to another discipline in the behavioral sciences. Not as far away as France, but only as far away as Harvard, where the Pierce professor of psychology is writing and demonstrating some extremely provocative things. I refer to Prof. B. F. Skinner, whose experiments with machines for teaching are having a slowly widening influence and whose writings are stirring up a lot of people. He has said, in a typically provocative sentence, "We do not fear education in this country because it is so weak; when it becomes strong, we call it brain washing." $\mathrm{He}$ is the apostle of the "reinforced" behavior pattern; that is, when you deal with animals of less complexity than man and you reinforce every action you want in, say, a pigeon with a reward, and meet every action you do not want with a deprivation, a punishment, or a lack of reward, you pretty soon have that pigeon doing just what you want when you want it to do it. The force of the analogy that what goes for a lower animal goes for a higher, within reasonable limitations, is very strong, and I hope I do Professor Skinner no injustice when I say that his position seems to be that the Age of Manipulation of man's reactions and emotions has at last arrived, and it behooves us to determine who is going to do the manipulating. "If we are to use the methods of science in the field of human affairs," says Professor Skinner, "we must assure that behavior is lawful and determined. We must expect to discover that what a man does is the result of specifiable conditions, and that once these conditions have been discovered, we can anticipate and to some extent determine his actions. ... This possibility is offensive to many people." I am not here to argue this point. It is an enormous one, and we have seen enough of the conditioning of man to know that the world will never be quite the same again.

But the promise of good things from these principles of learning and motivation is at least as great as the threat of bad things. In recent years other psychologists and anthropologists have begun to discover the ways in which early childhood experiences influenced the motiva- tions, the attitudes, and the behavior of both children and adolescents. The effects of different methods of child rearing are by no means as haphazard as they sometimes seem. A cold, punishing father tends to produce insecure and effeminate sons; a warm permissive mother tends to create independence and maturity in her daughters more readily than does a mother who holds up high standards but rarely rewards her child for achieving them.

These findings are applications of Professor Skinner's principles of learning. As behavioral scientists discover more and more such relationships, we can anticipate that medicine will be able to devote more of its energies to the prevention of misery and disease and proportionately less to the cure of conditions created earlier in patients' lives.

And in the midst of all this tremendous activity from biologists and psychologists, those nonbehavioral scientists, the chemists, have not been idle. Since the earlier discovery that some ancient remedies from India did have a scientific respectability after all, discovery after discovery has been made to the effect that what we think and what we are is to a large extent a chemical matter.

Pharmaceutical manufacturers are turning with respect to anthropologists to learn more about tribal customs and tribal remedies, in the very real expectation that rauwolfia serpentina is not the only folk medicine in which definite and wanted pharmacological properties are to be discovered and refined, as were the tranquilizers. A Nobel Laureate in chemistry, close by in the University of California, speaks of "molecular medicine" in the rising belief that almost everything that is wrong with us has its chemical antidote. And an American neurophysiologist, Ralph Gerard, of the University of Michigan, one-time fellow in the Center for Advanced Study in the Behavioral Sciences, has had his say on mental illness with the resounding phrase, "No twisted thought without a twisted molecule." So even a layman knows now that there is more than a suspicion, held in distinguished quarters, that even such a baffling mental affliction as schizophrenia can perhaps result from a twist in the body chemistry.

Discoveries seem to be bursting on us from every point of the compass. Can we lift the 
curse of mental affliction with chemistry, or with something an anthropologist finds in Australia? Is there only one disease, after all, as one physician has stoutly suggested, and its name is Stress?

For in the midst of our fascinating and hazardous world there is an imbalance almost everywhere. I notice it in my own field, which is the world of communication. Technology is ahead of content, and techniques are ahead of the intellect. It is true here, it is true there, it is true almost everywhere. We are long on knowledge and short on wisdom.

Despite brilliant exceptions, the study of behavior in relation to medicine has not yet had its innings. It is a truism which $I$ hope $I$ am quoting correctly when I say that two-thirds of all the patients a doctor sees do not have anything wrong with them that a painstaking physical examination and ever so many laboratory tests can distinctly reveal. They feel bad. Not all of them are candidates for extensive psychotherapy, but in case after case it is the interaction with someone or something external to them that is causing them the distress which they may interpret as "indigestion" or something the matter with the heart, or the lower back.

Everything I have read of the Stanford plan of education for medicine is full of excitement and promise. Stanford modestly says that its plans for the major remaking of its physical plant for teaching medicine "have coincided with nationwide scrutiny of the processes of medical education," and indeed we are all aware that this scrutiny is going on. A friend contrasts the life of a successful doctor with the life of a successful journalist-among a good many of whom I move daily in my job, dealing every hour of the day with matters of communication. The journalist complains that as his life goes on he learns more and more disrelated things. He knows a little, a very little, about almost everything. And he contrasts this with the life of a medical specialist, who comes to know more and more in an increasingly restricted area-and is likely to wind up a successful and honorable career, of great value to his fellow man, by feeling that somehow the world has passed him by.
Much remains to be done for the journalist, but what Stanford and some others propose to do for the doctor seems to be bright with hope. To be not only "healers of the sick" but "protectors of the well" is a noble aim. That it is the purpose to teach young doctors the importance of "lucid expression of thought in speech and writing and breadth of scholarly enterprise" as well as "independent and critical think. ing and the development of an inquiring mind" is most important, and I think such aims as lucid expression in speech and writing would have been notably absent from the catalogs of 25 years ago. But perhaps the single paragraph that I read with the most pleasure was: "Throughout the three years every effort is directed toward making the student aware of the patient as a person rather than as a defective organ system demanding some particular therapeutic approach. The influence of the total environment, including the influence of the physician himself, on the solution of a clinical problem is stressed."

I think every patient has been pleading for this for the last quarter century, although not able to express it with that much eloquence. One particularly wise physician began his examination of a woman patient recently by asking, "Is there any particular reason why you are dressed in black?" As a matter of fact, there was not, but the wisdom of asking such a question before applying the stethoscope was most impressive. We demand tremendous things of our physicians, and our demands are becoming even more tremendous. It is impressive that Stanford, like other modern institutions aware of a great change in our society, is responding to the demand, not shrugging it away as something impossible to provide.

I cannot imagine any such thought coming out of the University of Moscow as I found in the Stanford University program of education for medicine: "The public is making greater and greater demands upon the medical profession, and doctors are assuming that the physician's concern should be not only relief of the patient's immediate complaint but continuous assistance in achieving successful intellectual and emotional, as well as physical, adjustment to his environment and constitution." 
This is a huge order. It says, in effect: "Physician, make me happy and successful, within my limits, in addition to making me healthy." Yes, we know that the last 50 years have seen more progress in medicine than all the previous years since Hippocrates. But this is not enough. You must help solve some new problems which your new successes have created, as, for example, the problem of caring for the greater numbers of aged persons whose lives go on because of your efforts. The time is past when the term "social disease" is just a euphemism for syphilis. Now we use this term to describe crime, slums, poverty, and the problems of psychopathic or insufficient personalities. And we ask of the doctor that he add these problems to the problems he is already bearing on his shoulders.

It sounds like too much. Yet this medical center and its program and its ambitions are testimony that Stanford, for one, does not regard it as impossible. However great the burden, it is a burden that must be met somehow. And it looks as if the physician must be at the center of it. The imbalance I spoke of earlier, between our grasp of the sciences that deal with the external world and the sciences which are centered in man himself, grows more serious every day. We do better with the problems of outer space than we do with the problems of inner space; that is, what is contained within our own selves and our patterns of behavior. No less a thinker than Bertrand Russell has said that the scientists must close this gap or else, in his warning phrase, "Man will destroy himself with his halfway cleverness."

In effect, we are asking the physician to be the mediator between these two worlds-the world of external events and physical phenomena and the world of internal thoughts and feelings. No task could be more huge. It should not be thought for a minute that the physician is the only one who has become bogged down in overspecialization. We are witnessing the same splintering of knowledge and culture almost everywhere. Today we face the dangerous situation that one half of the world does not know what the other half is up to.

In the face of this splintering it seems to be left to medical education, as exemplified at this new Stanford Center, to be making the greatest effort to reintegrate what the past has split apart. It is indeed true that "the breadth of learning and understanding which characterized the outstanding physician of the past was increasingly threatened by the pressure to learn the details of medical science," to quote from the Stanford plan again, and that there now exists "a massive body of facts and principles impossible for one man to assimilate." But what is now being called "comprehensive medicine," a great new concept, seems to be arising. The Stanford plan looks to a heavy collaboration between the medical sciences and the behavioral sciences to help make this new comprehensive medicine operate to the end that medicine shall "keep in step with all the sciences that help to make the patient comprehensible." The medical man of the future cannot do everything by himself. But the anthropologist stands ready to help by the examination of customs and usages which might shed some light in dark places. The historian has value in his studies of how things were, and what changed them. The sociologist already makes a contribution to case medicine, and is ready to supply more help in more detailed studies of the effect of environment on continuing health or disease. The psychologists are already playing parts of greatly increasing importance in "scientific medicine," and one can certainly look to the time, now foreshadowed quite clearly, when the collaboration will be even closer than at present.

The late Dr. Alan Gregg once divided all public health activity into three periods. The first period he called the Era of Authority, which lasted from antiquity until the rise of scientific medicine. The second he called the Era of the Specialist, heavy with research experimentation and the treatment of specific health problems. The third era he called the Era of Ecology, which is the present era of the generalist as opposed to the specialist.

It is well to pause to define the word "ecology." It might be said to be the study of the inter-relationships of the organism-in this case man-with its total environment, both animate and inanimate. Medicine made a close approach to ecology earlier this century when Trudeau established his famous treatment for tuberculosis. His belief was that tuberculosis infection was just about 100 percent prevalent, 
and that therefore, since the avoidance of infection was impossible, the best thing to do was to establish a proper health environment, which would result in a sound and healthy body, resistant to this then ravaging disease. As we all know, tuberculosis is heavily on the wane, and many reasons are given for this triumph of medicine, with the usual heavy emphasis upon "miracle drugs." But I am told that in their moments of greatest candor, many physicians often wonder whether the causative factor in the downward drift of tuberculosis mortality lay in any of the artificial therapeutic regimes ever instituted, or whether an even stronger case could not be made out for changes in the human ecology such as the increased standard of living in this country due to better nutrition, housing, and conditions of employment.

Recent literature does clearly demonstrate how solid an impact the ecologic idea is now having upon human thought and activity within the domains of both the medical and the behavioral sciences. We see the word "interdisciplinary" used with increasing frequency to modify words like "research" and "program." Ecology has likewise made its appearance in the political sciences, with its emphasis upon regional planning, upon great metropolitan governments, and upon interdepartmental commissions.

In the great change that is now under way and in which Stanford stands well in the van, there is now not only a new interest in studying the whole person, there is a new interest in studying the well person instead of limiting analyses to the ill. Since no medical profession is ever going to be large enough to study all the well persons who need study while the demands of the sick are so pressing, it once again seems inevitable that the enlightened physician will want to call upon the sociologist, upon the cultural and physical anthropologists, and upon others whose organized contact is with large communal groups in a more or less ordinary way. In such a fashion we might divide our normal population into various groups, some of which appear more susceptible than others to certain chronic diseases. Hopefully, factors might be found which could modify this higher illness rate by studying the individuals in each group. Much of the hope for the eventual con- trol of chronic disease lies in the search for these factors which may be bound up with any one or more of many phases of man's daily complex interaction with his environment.

It is obvious that there cannot be a specific cure for conditions based on a host of ill-defined multiple causes. . Yet there may still be many solutions based upon a complete study of the many-sidedness of the complex human organism and its relation to its universe. It has been shown, for example, that senile psychosis is postponed when an aged individual has an active life and continues to interact frequently with his fellow man in a position of dignity. This has been demonstrated to such a degree that psychiatrists in the public health field urge senior citizens to remain active after retirement, even if financial reward is not a necessity.

There are many good examples of the ecologic treatment of disease in which the behavioral scientist must join with the medical man. The specialist in internal medicine is rarely able to cure his patient of essential hypertension. Yet by a modification of environment, by a kindling of his interest and taking a new look at life, the patient may continue on through decades of productive existence, having learned to work his serious disease into a new ecologic framework. The general problem of aging and the aged presents a major ecologic problem for our times. The need of care for this expanding population, sickness prone, financially poor, is not only great but is growing. Thus the products of increased expectation of life place a large burden upon the shoulders of the profession-a burden I am sure they will want to share.

Instead of disease and dependence, the theme of our times should emphasize health and selfsufficiency. No one who has lived the Biblical three score years and ten can be measured as well or ill by the same standards used for age 25 or even 40 . This aging patient with his hypertension, his arthritis, his nearsightedness, his failing hearing may be one thing, but ecologically speaking, his value to the world and to himself lies far more in his cheerfulness, his ability to read with strong glasses, the fact that his hearing aid does permit him to snatch conversation, and that his limbs are supple enough for him to tend to his own needs. If the past period is characterized by the terms "disease" 
and "prognosis," then the present ecologic one is calling upon the concepts of health and rehabilitation.

If man is to survive, now that he has the means of his total destruction, we must learn more about him-fast. Space is "finite but unbounded," the cosmologists tell us. I have some difficulty with this concept, but I accept it. Might this description also apply to man? We are said, also by the cosmologists, to be "doomed mariners on a shipwrecked planet." Is this view open to modification? If not, how shall we spend our remaining millions of years?

It is my earnest hope that with practice and experience, the behavioral sciences will step forth to the aid of medicine with the same alacrity that the physician displays when a call comes to him. Much is to be learned-but in comprehensive medicine, in the treatment of the patient as a human being rather than as an ambulatory symptom, in the recognition that environment and custom play as much a part in health as the principles of immunity, there is, it seems to me, a future great with promise. By uniting the medical school with the rest of the university, knowledge in the field of medicine and in the related biological, physical, and behavioral sciences will be extended, more largely integrated, and focused on our understanding of health and illness. By incorporating a modern community hospital and related services into the medical school complex, the science and the art of medicine can both be developed, and the university and the community can be brought more closely together. We are witnessing the beginning of a great contribution to the critical problems of community health.

\section{Computer Diagnosis of Heart Disease}

A computer in Washington, D.C., provides cardiographic diagnoses long-distance for heart patients in Veterans Administration hospitals in the Boston and New England areas.

Electronic pulse readings taken from heart patients are transmitted directly by telephone lines from the Veterans Administration hospital in West Roxbury, Mass., to an electronic data computer leased part-time by the Veterans Administration from the National Bureau of Standards. After a 6-second calculation, the diagnosis is flashed back to the West Roxbury hospital by voice over a regular long-distance telephone circuit.

The entire instant diagnosis, including recording from the patient, takes less than 10 minutes.

In addition to speed, the system also provides a much better and more thorough diag. nosis than would be possible for any physician unaided by the computer, according to Dr. Hubert V. Pipberger, chief of the Veterans Administration Eastern Research Support Center and assistant professor of medicine at the Georgetown University Medical School.
The computer can "read" and "evaluate" instantly all the recorded information about the patient, whereas the physician must consider each individual feature of the electrocardiogram. For example, three electrocardiographic leads, transmitted simultaneously by telephone, are analyzed in 27 dimensions - an insurmountable task so far as the doctor is concerned. Dr. Pipberger estimates that the computer diagnosis will be correct in from 90 to 95 percent of the cases computed.

The computer arrives at a differential diagnosis for each individual record, that is, all possible diagnoses are considered. Subsequently, the computer prints out a list of these diagnoses in the sequence of probabilities. The most likely diagnosis with the highest probability value is listed first, followed by all other diagnoses with their respective probabilities which are lower than that of the final diagnosis.

The Veterans Administration is studying the system for possible use in its other hospitals, especially those located some distance from metropolitan medical centers. 